\title{
Glypican-1 modulates the angiogenic and metastatic potential of human and mouse cancer cells
}

\author{
Takuma Aikawa, ${ }^{1}$ Chery A. Whipple, ${ }^{1}$ Martha E. Lopez, ${ }^{2}$ Jason Gunn, ${ }^{1}$ Alison Young, ${ }^{1}$ \\ Arthur D. Lander, ${ }^{2}$ and Murray Korc' ${ }^{1}$ \\ ${ }^{1}$ Department of Medicine, Department of Pharmacology and Toxicology, and the Norris Cotton Comprehensive Cancer Center, \\ Dartmouth Hitchcock Medical Center and Dartmouth Medical School, Hanover, New Hampshire, USA. 2Department of Developmental and Cell Biology, \\ University of California, Irvine, Irvine, California, USA.
}

\begin{abstract}
Cells isolated from many types of human cancers express heparin-binding growth factors (HBGFs) that drive tumor growth, metastasis, and angiogenesis. The heparan sulfate proteoglycan glypican-1 (GPC1) is a coreceptor for HBGFs. Here we show that both cancer cell-derived and host-derived GPC1 are crucial for efficient growth, metastasis, and angiogenesis of human and mouse cancer cells. Thus downregulation of GPC1 in the human pancreatic cancer cell line PANC-1, using antisense approaches, resulted in prolonged doubling times and decreased anchorage-independent growth in vitro as well as attenuated tumor growth, angiogenesis, and metastasis when these cells were transplanted into athymic mice. Moreover, athymic mice that lacked GPC1 exhibited decreased tumor angiogenesis and metastasis following intrapancreatic implantation with either PANC-1 or T3M4 human pancreatic cancer cells and fewer pulmonary metastases following intravenous injection of murine B16-F10 melanoma cells. In addition, hepatic endothelial cells isolated from these mice exhibited an attenuated mitogenic response to VEGF-A. These data indicate that cancer cell-and host-derived GPC1 are crucial for full mitogenic, angiogenic, and metastatic potential of cancer cells. Thus targeting GPC1 might provide new avenues for cancer therapy and for the prevention of cancer metastasis.
\end{abstract}

\section{Introduction}

Pancreatic ductal adenocarcinoma (PDAC) is the fourth leading cause of cancer death in the United States and is responsible for over $20 \%$ of deaths due to gastrointestinal malignancies in other industrialized countries (1). Although recent diagnostic and therapeutic advances have slightly prolonged the survival of patients with PDAC, the overall prognosis of these patients is still extremely poor $(1,2)$. With some exceptions, long-term survival is often limited to patients who have surgery at an early stage of the disease. However, all too often the diagnosis of PDAC is established when metastases have already occurred, excluding these patients from attempts at curative resection $(1,2)$. There is an urgent need, therefore, for an improved understanding of the molecular mechanisms that contribute to pancreatic tumor growth and metastasis.

Proteoglycans are ubiquitous macromolecules that are found on cell surfaces, in the extracellular matrix, and in connective tissues and that have been implicated in promoting tumor growth (3-5). Proteoglycans consist of specific core proteins to which a variable number of polysaccharide chains are covalently attached. These polysaccharide chains, or glycosaminoglycans (GAGs), are variable in type and size and typically consist of disaccharide repeats of D-glucuronic or L-iduronic acid and either $N$-acetylglucosamine or $N$-acetylgalactosamine (3-6). GAGs have a high charge density

Nonstandard abbreviations used: GAS, GPC1 antisense-transfected; GPC1, glypican-1; GPI, glycosylphosphatidylinositol; HB-EGF, heparin-binding EGF-like growth factor; HBGF, heparin-binding growth factor; HS, heparan sulfate; HSPG, HS proteoglycan; MEF, murine embryonic fibroblast; PCNA, proliferating cell nuclear antigen; PDAC, pancreatic ductal adenocarcinoma.

Conflict of interest: The authors have declared that no conflict of interest exists. Citation for this article: J. Clin. Invest. 118:89-99 (2008). doi:10.1172/JCI32412. and exhibit marked diversity due to variations in the disaccharides and sites of sulfation (7). In addition to heparin and heparan sulfate (HS), GAGs may consist of chondroitin or dermatan sulfates, keratan sulfate, or hyaluronan. The aberrant expression of a number of these HS proteoglycans (HSPGs) has been implicated in a variety of human malignancies (5). In this regard, the roles of 2 types of HSPGs, the glypicans and syndecans, have been examined in great detail because both of these families of polypeptides carry the majority of the HS on mammalian cells.

There are 6 glypicans, which are attached to the plasma membrane via glycosylphosphatidylinositol (GPI) anchors, and 4 syndecans, which are transmembrane proteins, all encoded by separate genes (3-9). Glypicans and syndecans participate in the regulation of cell-cell interactions and the interactions between heparin-binding growth factors (HBGFs) and their cognate high-affinity receptors (5-6, 8-10). Among the 6 members of the glypican family, only glypican-1 (GPC1) is overexpressed in PDAC, and attenuation of GPC1 expression dampens the mitogenic responses to HBGFs and slows pancreatic tumor growth in vivo $(11,12)$.

In the present study we compare the consequences of GPC1 suppression in the cancer cells and in the mouse host. Decreased GPC1 expression in PANC-1 cells was associated with a significant decrease in cell doubling time and attenuated anchorage-independent growth. In athymic mice, the same cells exhibited decreased subcutaneous and intrapancreatic tumor growth and attenuated angiogenesis and metastasis by comparison with sham-transfected PANC-1 cells. Moreover, PANC-1- and T3M4-derived intrapancreatic tumors exhibited attenuated angiogenesis and metastasis in athymic GPC1-null mice when compared with tumors in WT athymic mice. The GPC1-null mice also developed fewer pulmonary metastases following intravenous injection of murine B16-F10 


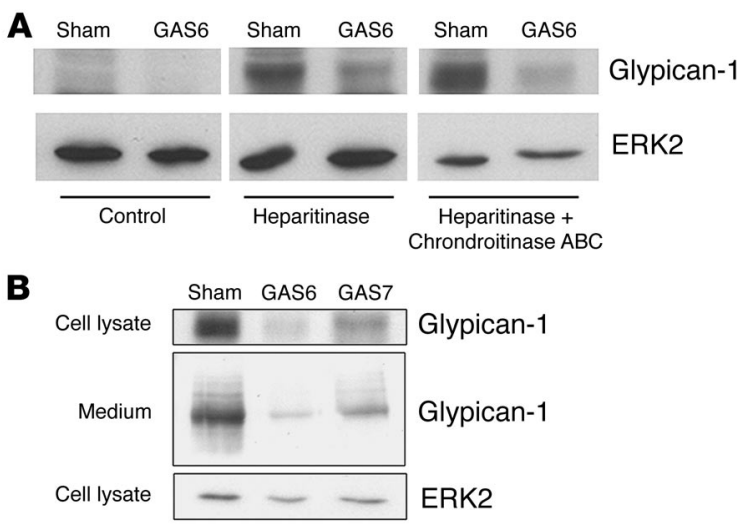

melanoma cells. Thus both cancer cell- and host-derived GPC1 are important for tumor growth, angiogenesis, and metastasis.

\section{Results}

Effects of GPC1 levels on the in vitro growth properties of PANC-1 cells. To assess cellular GPC1 protein levels, immunoblotting with an anti-GPC1 antibody was performed using total cell lysates from sham-transfected and GPC1 antisense-transfected (GAS) clones of PANC-1 cells that were incubated in the absence or presence of deglycanating enzymes. Due to the poor binding of glycanated GPC1 to blotting membranes, it either fails to appear on immunoblots or appears as a series of faint bands and broad high-molecular-weight smears (11). As expected, the antibody detected the presence of multiple GPC1 bands in the absence of enzymatic treatment (Figure 1A). By contrast, following heparitinase digestion of the HSs, a broad major band was readily visible in sham-transfected cells (Figure 1A). The intensity of the band was increased slightly when the digestion was performed in the presence of both heparitinase and chondroitinase $\mathrm{ABC}$, an enzyme that removes chondroitin sulfates. Thus the majority of GPC1 molecules contained only small amounts of chondroitin sulfate (13), and the anti-GPC1 antibody recognized human GPC1 in a highly specific manner. As was the case with whole

\section{Figure 2}

Cell growth assays. (A) Effects of GPC1 levels on basal anchorage-independent growth. Sham-transfected PANC-1 cells and GPC1 antisense-expressing clones were seeded in 6-well plates (3,000/well) in complete medium containing $0.3 \%$ agar. After 14 days, colonies having more than 20 cells were counted. Data indicate the mean \pm SEM of triplicate determinations from 3 experiments. ${ }^{*} P<0.01$ compared with sham-transfected cells. (B) Effects of GPC1 levels on growth factor-stimulated anchorage-independent growth. Sham-transfected (filled symbols) and GPC1 antisense mRNA-expressing PANC-1 cells (open symbols) were seeded in 6 -well plates $(3,000 /$ well) in serum-free medium containing $0.3 \%$ agar. Serum-free medium containing $1 \mathrm{nM}$ HB-EGF, FGF2, EGF, or IGF-1 was added every 4 days. After 14 days, colonies having more than 20 cells were counted. Data are expressed as percentage change from the respective controls (mean \pm SEM) of 3 determinations per experiment from 3 separate experiments. ${ }^{\star} P<0.05$ and ${ }^{* \star} P<0.03$ compared with control.

\section{Figure 1}

Effects of GPC1 antisense expression on GPC1 protein levels. (A) Effects of enzymatic treatment on immunoblotting. Sham-transfected cells and GPC1 antisense-expressing cells (clone GAS6) were incubated in the absence or presence of the indicated enzymes and subjected to immunoblotting using affinity-purified rabbit anti-GPC1 antibody as reported in Methods. (B) Total cell lysates from shamtransfected and from both antisense-expressing clones as well as the corresponding conditioned media were incubated with heparitinase and chondroitinase $\mathrm{ABC}$ and subjected to immunoblotting as described above. Membranes from cell lysates were reprobed with an anti-ERK2 antibody to confirm equivalent loading of lanes. Each panel is representative of 2 distinct experiments. cell lysates, the GAS6 clone released smaller amounts of GPC1 into the medium than the GAS7 clone, and both clones released less GPC1 than sham-transfected cells (Figure 1B).

PANC-1 cells express many growth factors, including several HBGFs such as heparin-binding EGF-like growth factor (HBEGF) and amphiregulin $(14,15)$. Two types of experiments were performed to determine whether GPC1 levels facilitated autocrine growth stimulation in these cells. First, the effects of altering GPC1 expression on cell doubling times were examined. Sham-transfected cells exhibited a doubling time of 22.5 hours. By contrast, the GAS clones GAS6 and GAS7 displayed significantly longer doubling times ( $33.0 \mathrm{~h}$ and $28.6 \mathrm{~h}$, respectively). Second, the consequences of lowering GPC1 expression on anchorage-independent growth were assessed by monitoring colony formation in soft agar (Figure 2A).
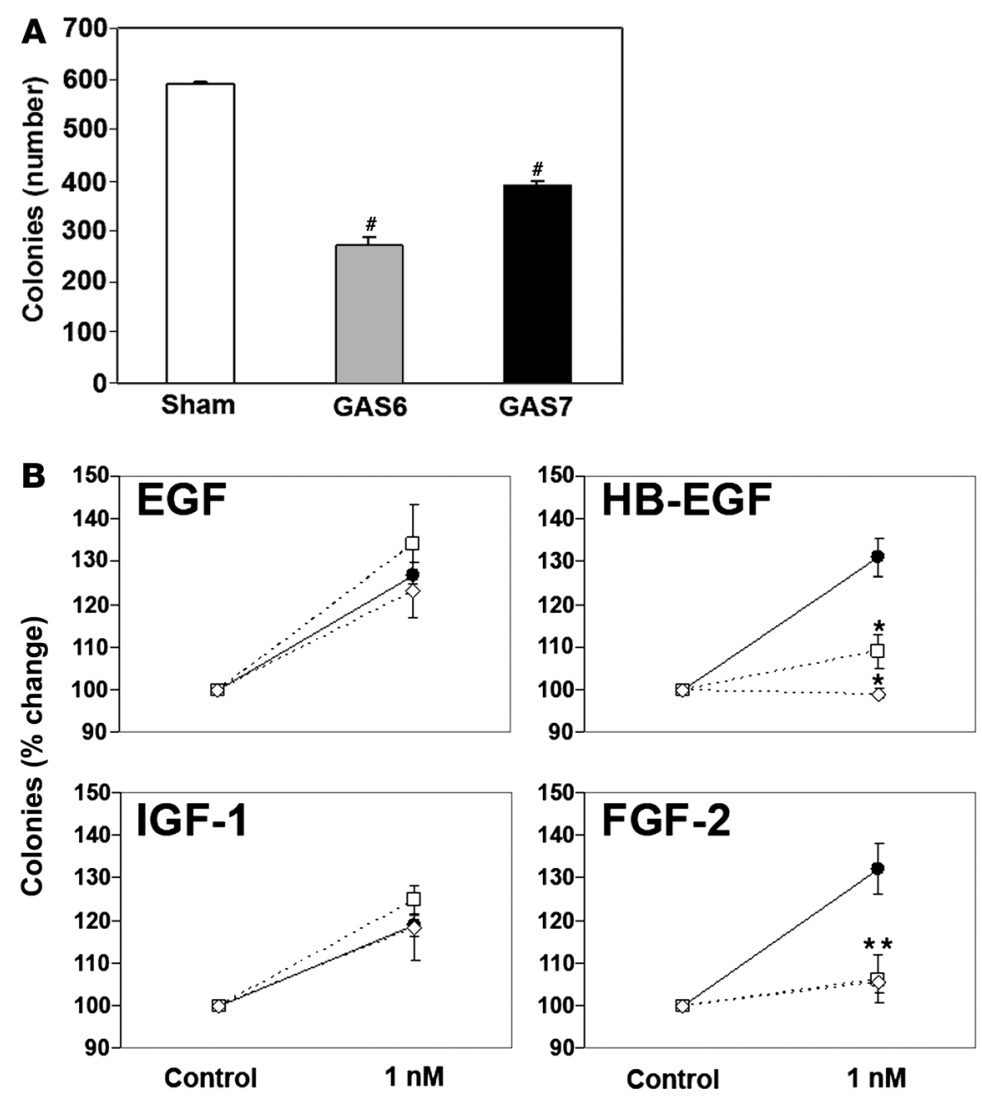
A
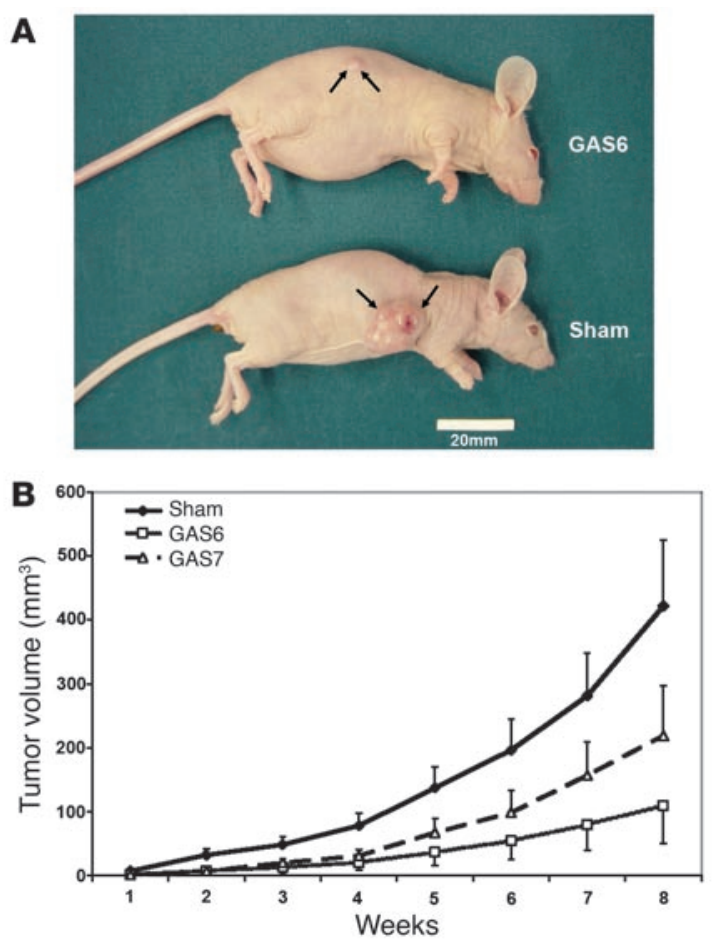

Thus under similar incubation conditions, sham-transfected cells formed $591 \pm 5$ colonies, whereas GAS6 and GAS7 clones formed $273 \pm 14$ and $392 \pm 6$ colonies, respectively. To assess whether GPC1 levels modulated growth factor responsiveness in an anchorageindependent environment, the effects of 2 HBGFs (FGF-2 and HBEGF) and 2 non-HBGFs (EGF and IGF-I) on cell growth in soft agar were determined (Figure 2B). FGF-2 and HB-EGF increased colony formation of sham-transfected PANC-1 cells, and this effect was markedly attenuated in GAS clones. In contrast, the growth stimulatory action of EGF and IGF-I were similar in both groups of cells (Figure 2B). Taken together, these observations suggest that cancer cell-derived HBGFs require the presence of GPC1 for efficient autocrine-paracrine growth stimulation.

Effects of GPC1 levels on the in vivo growth properties of PANC-1 cells. To compare the tumorigenicity of GAS PANC-1 cells with shamtransfected cells, $2 \times 10^{6}$ sham-transfected cells, GAS6, or GAS7 cells were injected subcutaneously at 1 site per athymic mouse. GAS6 cells formed consistently smaller tumors than GAS7 cells (Figure 3A), and both GAS6 and GAS7 cells formed smaller tumors than sham-transfected cells (Figure 3B). At 8 weeks following tumor injection, there was a $74 \%$ decrease in growth in the

\section{Figure 4}

GPC1 expression in tumor xenografts. (A) Immunoblotting. Tumors from sham-transfected and GAS PANC-1 cells (GAS6 and GAS7) were homogenized and incubated with control buffer, heparitinase, or heparitinase and chondroitinase $A B C(C h-A B C)$. Protein lysates were subjected to immunoblotting using affinity-purified rabbit anti-GPC1 antibody as reported in Methods. Membranes from cell lysates were reprobed with an anti-ERK2 antibody to confirm equivalent loading of lanes. (B) Densitometric analysis. Frozen lysates for immunoblotting from 6 sham, 5 GAS6, and 4 GAS7 tumors were subjected to densitometry. ${ }^{*} P<0.005$ compared with sham.

\section{Figure 3}

Effects of GPC1 levels on tumor growth. (A) Representative tumors. GAS6 cells consistently formed smaller tumors than sham-transfected cells. The mice bearing GAS tumors appeared healthy. By contrast, the mice bearing tumors from sham-transfected cells had to be terminated due to their cachectic appearance, tumor size, and tendency of the tumors to develop surface ulcerations. (B) Tumor growth curves. Exponentially growing $\left(2 \times 10^{6}\right)$ sham-transfected PANC-1 cells (filled diamonds) and GAS7 (open triangles) and GAS6 (open squares) cells were injected subcutaneously in athymic mice, and tumor growth was measured weekly. Tumor volume was determined by the equation: volume $=(I \times h \times w) \times \pi / 4$, where $/$ is length, $h$ is height, and $w$ is width of the tumor. Data are mean \pm SEM from 9 tumors for sham-transfected PANC- 1 cells and for each of the 2 GAS clones.

9 GAS6-derived tumors and a $48 \%$ decrease in the 9 GAS7-derived tumors, by comparison with tumors from sham-transfected cells. Due to the need for multiple comparisons at multiple time points, statistical significance was determined using ANOVA, followed by Tukey's honest significant difference (HSD) test of the comparisons that were deemed significant by ANOVA, with $P<0.05$ taken as statistically significant. This analysis indicated that GAS6-derived tumors were significantly smaller $(P<0.05)$ than the tumors derived from sham-transfected cells at all measured time points. By contrast, GAS7-derived tumors were only significantly different at 2 weeks after cancer cell injection $(P<0.05)$. However, analysis of the combined data from all 18 GAS tumors at the 8 -week time point revealed a significant decrease in tumor volumes at 8 weeks $(P<0.03)$ when compared with the 9 sham-derived tumors.

Immunoblotting of whole tumor lysates (Figure 4A), followed by densitometric analysis (Figure 4B), was carried out next in order to compare GPC1 protein levels in the tumors from all 3 groups. This analysis revealed that GPC1 protein levels were decreased by $48 \%$ $(P<0.005)$ and $34 \%(P=0.06)$ in the tumors derived from GAS6
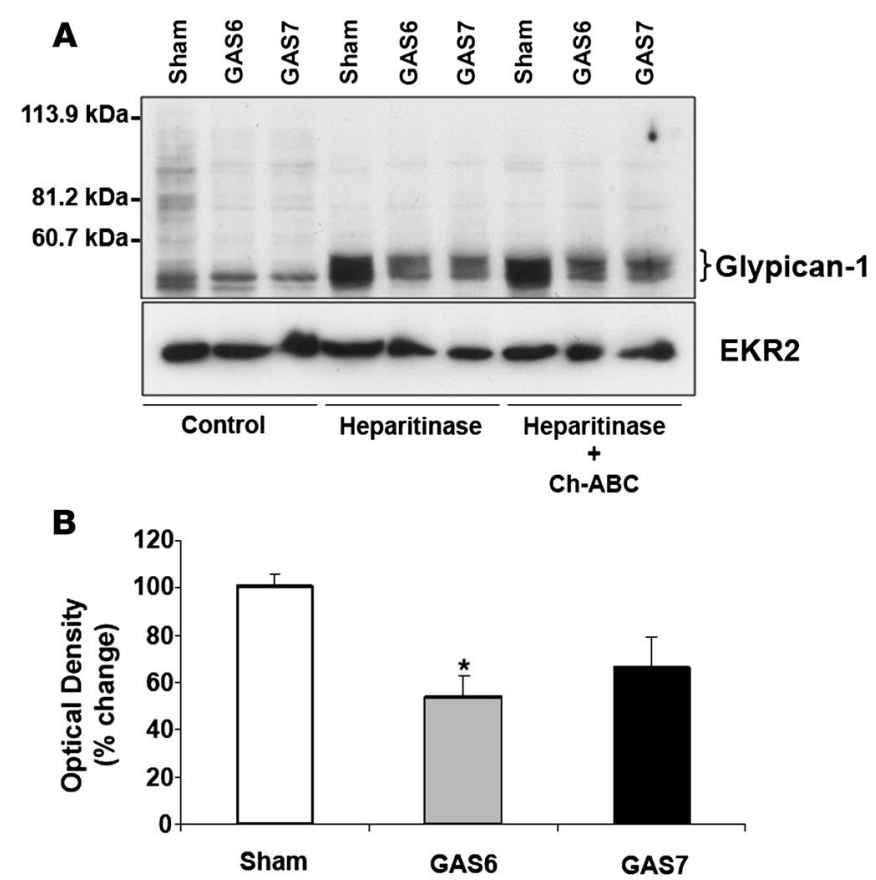
A

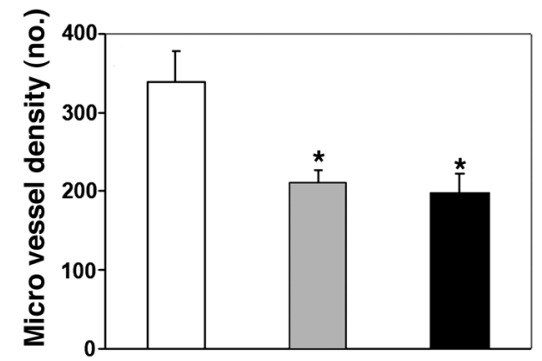

B

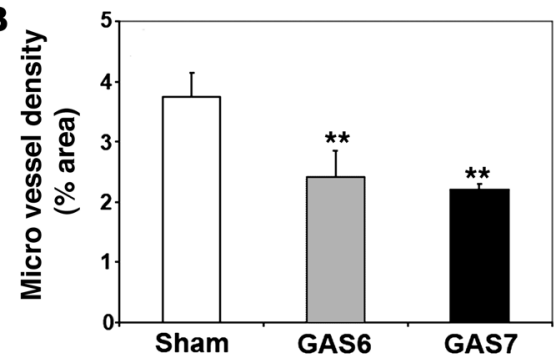

and GAS7 clones, respectively, by comparison with tumors arising from sham-transfected cells. Thus GPC1 levels in tumors derived from antisense-expressing clones remained low throughout the in vivo study, but this decrease did not achieve statistical significance in the GAS7-derived tumors, due in part to the somewhat greater variability in GPC1 levels observed in these tumors.

Tumor vessel counts, cell apoptosis, and proliferation. To assess the effects of decreased endogenous GPC1 levels on tumor angiogenesis, immunohistochemical staining of tumors that were removed 8 weeks following cancer cell injection was performed with anti$\mathrm{CD} 31$ antibodies. There was a readily visible decrease in the number of CD31-positive cells in tumors formed by GAS6 and GAS7 clones by comparison with tumors formed by sham-transfected cells (data not shown). Morphometric analysis of vessel number revealed a 38\% $(P<0.05)$ and a $42 \%(P<0.05)$ decrease in microvessel densities in the tumors formed by the 2 clones by comparison with the tumors from sham-transfected cells (Figure 5A). Similar results were observed on the basis of the area occupied by CD31positive cells (Figure 5B), with GAS6 and GAS7 clones exhibiting decreases of $36 \%(P<0.001)$ and $41 \%(P<0.001)$, respectively. Cell proliferation, as determined by monitoring proliferating cell nuclear antigen (PCNA) immunoreactivity, was significantly decreased in GAS6- $(P<0.005)$ but not GAS7-derived tumors (Figure 6). By contrast, immunohistochemical analysis for apoptosis using the TUNEL assay failed to reveal a significant difference between the 3 groups of tumors (data not shown), indicating that the observed differences in tumor size were not due to any differences in susceptibility to apoptosis.

Effect of GPC1 levels on MAPK activation in the tumors. Inasmuch as many HBGFs frequently exert their mitogenic effects through

\section{Figure 6}

Effects of GPC1 levels on PCNA immunoreactivity in subcutaneous tumors. Morphometric analysis of PCNA immunoreactivity was performed as described in Methods, using 10 tumors from sham-transfected PANC-1 cells, 6 tumors from GAS6 cells, and 9 tumors from GAS7 cells. Data are means \pm SEM. ${ }^{*} P<0.01$ compared with sham.

\section{Figure 5}

Effects of GPC1 levels on CD31 immunoreactivity in subcutaneous tumors. (A) Analysis of vessel number. Morphometric analysis of vessel number was performed as described in Methods, using an antiCD31 antibody. Data are based on immunohistochemical staining of 10 tumors from sham-transfected PANC- 1 cells, 7 tumors from GAS6 cells, and 10 tumors from GAS7 cells. (B) Analysis of vessel area. Morphometric analysis on the same tumors was carried out based on the area occupied by the vessels. Data are the means \pm SEM. ${ }^{*} P<0.05$ and ${ }^{* *} P<0.01$ compared with sham.

activation of the MAPK pathway, it was of interest to determine whether MAPK activation was attenuated in the tumors that arose from GPC1 antisense- expressing PANC-1 cells. Accordingly, immunoblotting with anti-phospho-MAPK antibody was performed next (Figure 7). The levels of both forms of phosphoMAPK (phospho-ERK1 and -ERK2) were significantly decreased in tumors from both GAS6 $(P<0.05)$ and GAS7 clones $(P<0.05)$ by comparison with the corresponding levels in tumors derived from sham-transfected cells. Thus the ability to activate MAPK was significantly altered even in tumors whose GPC1 levels were only modestly decreased.

Effect of GPC1 levels on the expression of Tie2 receptor and ligands. Angiopoietin- 1 and -2 are ligands that bind the Tie2 tyrosine kinase receptor, which is most often expressed by endothelial cells (16) but is also expressed in some cancer cells such as breast cancer and glioma cells $(17,18)$. While angiopoietin-1 generally acts as an agonist of Tie 2 and angiopoietin-2 generally acts as an antagonist $(16,19)$, at high ligand concentrations angiopoietin-2 can also act as an agonist (20), and both ligands have been implicated in tumor angiogenesis because of their survival-promoting effects on endothelial cells and because they stimulate the sprouting of new blood vessels in the presence of high VEGF-A levels (20-24). VEGF-A, whose expression is increased in PDAC (25), is known to upregulate angiopoietin expression (26), and VEGF-A actions as well as angiopoietin actions require the presence of HSPGs (27). It was of interest, therefore, to assess the expression of angiopoietins, Tie2, and VEGF-A in sham-transfected and GAS6 cells as well as in the tumors derived from these cells. By quantitative real-time PCR, angiopoietin-1 levels were increased in cultured GAS6 cells when compared with shamtransfected cells, whereas angiopoietin-2 and Tie 2 mRNA levels were significantly decreased in these cells and VEGF-A mRNA levels were not altered (Figure 8). By contrast, the levels of all 4 mRNA moieties were significantly decreased in tumors from

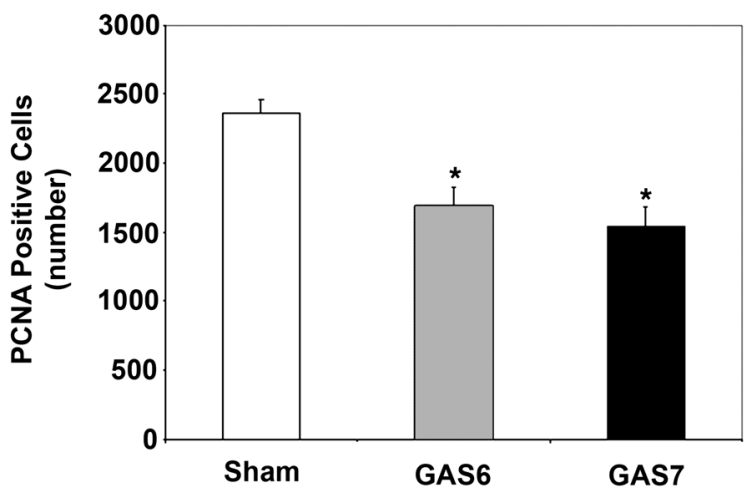




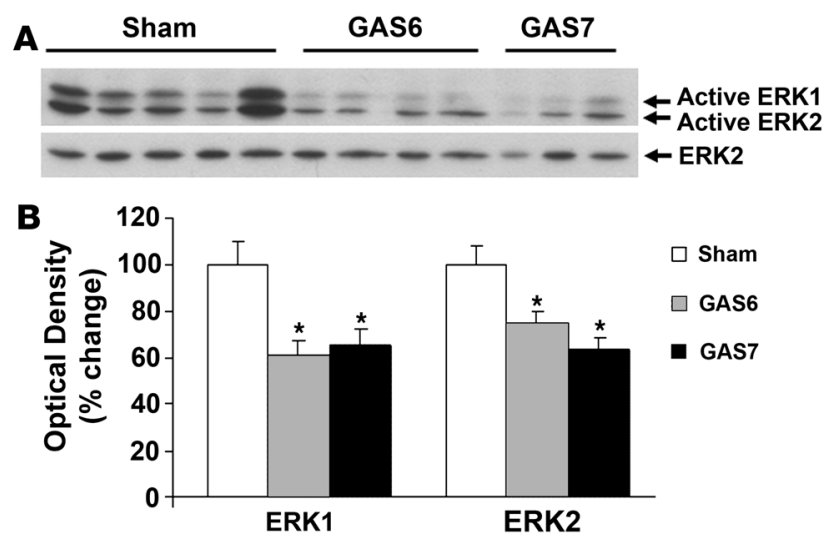

GAS6 and GAS7 cells by comparison with tumors from shamtransfected PANC-1 cells (Figure 9).

To determine whether angiopoietin- 1 and -2 and Tie 2 were expressed in the cancer cells within the tumor mass, immunostaining was next carried out in the tumors from sham-transfected cells. Angiopoietin-1 and -2 as well as Tie 2 were present in a heterogeneous pattern within the cancer cells (Figure 10) and in the endothelial cells within the tumor mass. Both angiopoietins exhibited cytoplasmic distribution in the cancer cells, whereas Tie2 immunoreactivity was distinctly membranous.

Effect of GPC1 levels on tumor growth and metastasis in an orthotopic model. To determine whether GPC1 levels in the cancer cells dictated the extent of tumor metastasis, $2 \times 10^{6}$ sham-transfected or GAS6 and GAS7 cells were injected into the pancreas of nude mice. Six weeks after tumor inoculation, the intrapancreatic tumors of sham-transfected PANC-1 cells were significantly larger than those arising from either GAS6 or GAS7 clones (Table 1). All 10 tumors arising from sham-transfected cells were associated with local and/or mesenteric node metastasis, and 2 mice exhibited peritoneal dissemination and ascites (Table 1). By contrast, only 3 of 20 tumors arising from GAS cells yielded lymph node metastasis, and none exhibited mesenteric involvement, peritoneal spread, or ascites (Table 1).

Tumor growth and metastasis in a GPC1-knockout model. To assess the role of endogenous GPC1 on tumor growth, sham-transfected PANC-1 cells were injected into the pancreas of both WT nude mice and GPC1-null mice on the same athymic background (Table 2). By 10 weeks after tumor inoculation, all 7 WT mice appeared ill, leading to termination of the experiment, and all harbored intrapancreatic tumors, which formed extensive metastases. The eighth mouse in this group died of unknown causes 2 weeks following cancer cell injection and was therefore not evaluated. By contrast, only 5 of 8 GPC1 $1 /$ mice formed tumors, and the mean volume of these 5 tumors was significantly smaller than the mean volume of the 7 tumors in the WT mice (Table 2). The tumors in the GPC1/group also exhibited attenuated angiogenesis (52\% decrease in

\section{Figure 8}

Effects of GPC1 levels on the expression of proangiogenic factors in PANC-1 cells in culture. RNA extracted from sham-transfected PANC-1 cells and GAS6 cells was subjected to real-time quantitative PCR. Relative expression levels were determined in triplicate. Data are means \pm SEM from 3 different experiments. ${ }^{*} P<0.01$ compared with the corresponding sham.

\section{Figure 7}

Effects of GPC1 levels on phospho-MAPK in subcutaneous tumors. (A) Immunoblotting for active ERK1/2. Lysates from 10 tumors from sham-transfected PANC-1 cells, 8 tumors from GAS 6 cells, and 6 tumors from GAS7 cells were subjected to immunoblotting with antiphospho-MAPK antibody as described in Methods. (B) Densitometric analysis. Band intensities for active ERK1 and active ERK2 were normalized to total ERK2 (loading control). Data are means \pm SEM. ${ }^{\star} P<0.05$ compared with sham.

microvessel density; $P<0.0005$ ), and none of these tumors formed metastases (Table 2). Moreover, all the mice in this group appeared healthy at the end of the experiment.

To confirm that host GPC1 was not uniquely important for PANC-1 cells, we next compared the growth of T3M4 pancreatic cancer cells in WT and GPC1-null nude mice (Table 3). T3M4 cells grow more rapidly in vivo than PANC- 1 cells. Therefore, only $2 \times 10^{5}$ T3M4 cells were injected into each pancreas, and the experiment was terminated 4 weeks later due to the concern that rapid tumor growth would be unpredictably lethal. Although at this time point tumor volumes were similar in both groups, the WT mice exhibited multiple metastatic lesions (Figure 11), whereas the GPC1/were devoid of metastases (Table 3). Moreover, as in the case of the tumors derived from PANC-1 cells, angiogenesis was decreased by $52 \%(P<0.04)$ in the T3M4-derived tumors in $\mathrm{GPC}^{-/-}$mice by comparison with tumors in the WT mice (Table 3).

To determine whether GPC1-null mice exhibited an attenuated capacity to form metastases from nonpancreatic cancer cells, the murine B16-F10 pulmonary metastasis model was examined next (Figure 12). By comparison with WT mice, the melanoma cells formed $62 \%$ fewer pulmonary metastases in the GPC1-null mice $(P<0.006)$.

In vitro effects of growth factors on endothelial cell proliferation. To determine whether endothelial cells isolated from GPC1 $1 /-$ mice exhibit normal proliferative responses, proliferation assays were performed next, using endothelial cells isolated from the liver of WT and GPC1-null mice (Figure 13). VEGF-A (1 nM) caused a significantly greater increase in cell proliferation in the WT-derived endothelial cells by comparison with the GPC1/- cells. To confirm the selective loss of GPC1 in endothelial cells and murine embryonic fibroblasts (MEFs) isolated from GPC1-null mice, quantitative PCR was performed next, using RNA prepared from the respective cells. As expected, both cell types, when isolated from GPC1-null mice, exhibited complete loss of the GPC1 mRNA transcript, whereas the levels of GPC2-GPC6 and syndecans 1-4 were similar in the endothelial cells and MEFs isolated from WT and GPC1-null mice (data not shown).

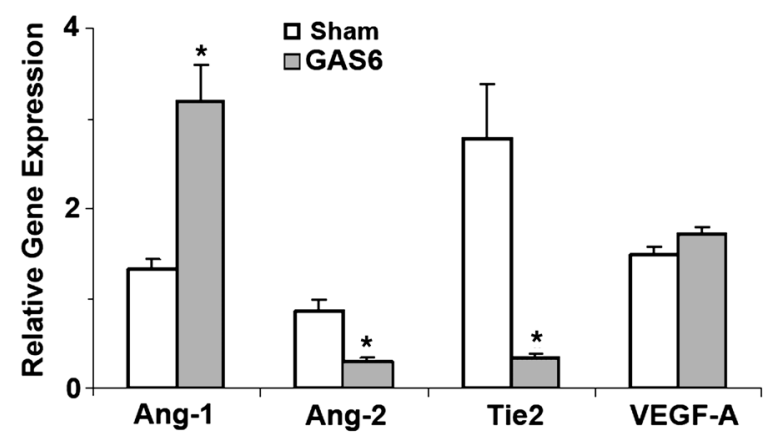




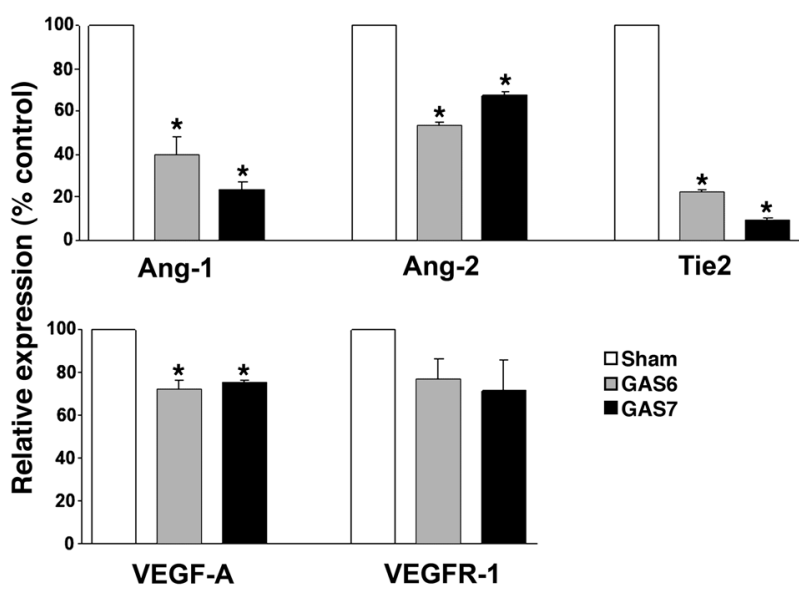

\section{Discussion}

PDAC is characterized by multiple genetic alterations, including a high frequency of mutations in the K-ras oncogene, the p53 and Smad4 tumor suppressor genes, and the p16 cell cycle inhibitory gene (28). In addition, there is overexpression of multiple growth factors and their cognate tyrosine kinase receptors, which act to promote mitogenesis, cancer spread and invasiveness, and angiogenesis (29). Many of these growth factors, including FGFs, HB-EGF, amphiregulin, hepatocyte growth factor, the high-molecular-weight forms of VEGF-A and TGF- $\beta$ s either are HBGFs and/or interact with HSPGs. Oftentimes, these interactions lead to enhanced binding with the respective highaffinity receptors $(30,31)$.

We previously reported that the expression of the HSPG GPC1 is upregulated in PDAC but that other members of the glypican family are not overexpressed in this malignancy (11). We also demonstrated that GPC1 exerts a promitogenic role in pancreatic cancer cells and showed that treatment with PIPLC, which cleaves the GPI anchor of GPC1, abrogates the mitogenic responses of PANC-1 and COLO-357 pancreatic cancer cells to FGF-2 and HBEGF, 2 HBGFs that are commonly overexpressed in PDAC (11). Furthermore, we determined that expression of a form of GPC1 engineered to possess a transmembrane domain instead of a GPI anchor conferred resistance to the inhibitory effects of PIPLC on growth factor responsiveness and that transfection of a GPC1 antisense construct attenuated the mitogenic response to FGF-2 and HB-EGF (11). In contrast, neither PIPLC treatment nor GPC1 antisense expression altered the response of the cancer cells to the non-HBGFs EGF and IGF-1. Together these observations suggested that GPC1 may play a crucial role in enhancing the mitogenic actions of HBGFs in pancreatic cancer cells.

In the present study, suppression of GPC1 expression in PANC-1 cells led to markedly prolonged doubling times, decreased basal anchorage-independent growth, and a failure of exogenously added HB-EGF and FGF-2 to enhance anchorage-independent

\section{Figure 10}

Angiopoietin and Tie2 immunohistochemistry. Immunohistochemical staining for angiopoietin-1, angiopoietin-2, and Tie2 was performed as described in Methods. (A) Angiopoietin-1; (B) angiopoietin-2; (C) Tie2; (D) control staining in the absence of a primary antibody. Original magnification, $\times 100$ (A and D); ×200 (B and C).

\section{Figure 9}

Effects of GPC1 levels on the expression of proangiogenic factors in PANC-1-derived subcutaneous tumors. RNA extracted from tumors derived from sham-transfected PANC-1 cells and 2 GPC1 antisense PANC-1 clones was subjected to real-time quantitative PCR. Relative expression levels were determined in triplicate. Data are the means \pm SEM from 6 sham and 4 GAS6 and 3 GAS7 tumors. ${ }^{\star} P<0.01$ when compared with the corresponding sham.

growth. However, in the subcutaneous athymic mouse model, only GAS6-derived tumors exhibited attenuated tumor growth and a significant decrease in cancer cell proliferation, whereas the corresponding values in GAS7-derived tumors did not achieve statistical significance. By contrast, GPC1 suppression was associated with attenuated MAPK activation in both GAS6- and GAS7-derived tumors and with a marked decrease in the microvessel density. Taken together, these observations indicate that GPC1 allows for efficient autocrine and paracrine activation of growth-promoting pathways in pancreatic cancer cells, that in the face of a sufficient decrease in GPC1 the in vivo levels of non-HBGFs such as EGF and IGF-1 are not adequate for overcoming the decrease in HBGFdependent mitogenic signaling, and that both MAPK activation and tumor angiogenesis are exquisitely dependent on the presence of GPC1, perhaps because sustained MAPK activation by HBGFs is GPC1 dependent (32).

In addition to a decrease in microvessel density, the tumors from the GPC1 antisense-expressing cells exhibited a significant decrease in Tie2, angiopoietin-1, angiopoietin-2, and VEGF-A mRNA levels (Figure 9). In the case of Tie 2 and angiopoietin-2, this decrease was in part due to a cell-autonomous attenuation in their expression in the GPC1 antisense-expressing GAS6 cells in culture (Figure 8). However, angiopoietin-1 mRNA levels were increased in GAS6 cells that were in culture, underscoring the well-recognized divergence in the regulation of angiopoietin-1 expression from that of angiopoietin-2 (33). By contrast, angiopoietin-1 expression was decreased in the tumors, indicating that in vivo environment pathways that upregulate angiopoietin-1 are highly dependent on the presence of GPC1. Inasmuch as quantitative PCR analysis was performed using primers for human sequences of these mRNA moieties, these measurements most likely reflected expression in the cancer cells, which was confirmed by immunostaining.
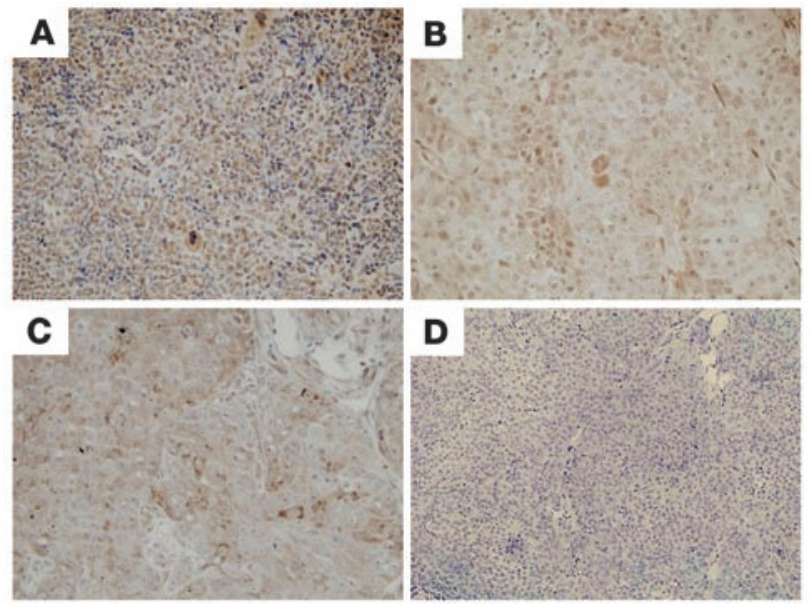

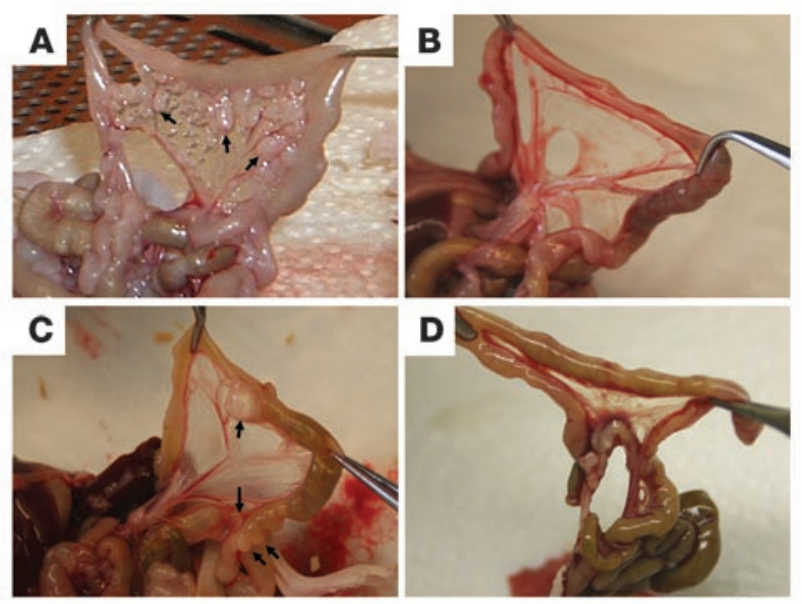

Four mechanisms may explain the observed decrease in tumor angiogenesis (Figure 14). First, a decrease in levels of GPC1 in the cancer cells leads to decreased in vivo expression of VEGF-A and angiopoietin-1 and -2, which are necessary for an efficient proangiogenic milieu within the tumor mass. Second, GPC1 on the surface of the cancer cells can act in trans to promote angiogenesis (34). Thus when these cells express low levels of GPC1, there is an attenuation in the actions of proangiogenic HPGFs $(35,36)$ on the tumor endothelial cells adjacent to the cancer cells. Third, GPC1 is readily shed by pancreatic cancer cells (11). Therefore, it is also possible that decreased shedding of GPC1, as observed with the GAS cells, acts to impede tumor angiogenesis. Fourth, GPC1 produced by fibroblasts in the tumor microenvironment (11) and by endothelial cells (37) is necessary for efficient tumor angiogenesis, as evidenced by the present findings in GPC1-null mice. The importance of host endothelial cell HSs in tumor angiogenesis was demonstrated in a recent study in which mice carrying an endothelial targeted deletion of $\mathrm{N}$-acetylgluocsamine $\mathrm{N}$-deacetylase/ $\mathrm{N}$-sulfotransferase (Ndst1) exhibited decreased $N$-sulfation of glusoamine residues and, consequently, attenuated tumor angiogenesis (27). Inasmuch as the $\mathrm{Ndst} 1$ deletion was restricted to endothelial cells, this study underscores the cell-autonomous effects of HSs with respect to tumor angiogenesis.

The tumor microenvironment is of crucial importance for pancreatic cancer growth and metastasis, as evidenced by the fact that the subcutaneous injection of pancreatic cancer cells in athymic mice does not yield metastases, whereas their intrapancreatic injection produces metastatic lesions. Using this orthotopic model, we determined that both GAS6 and GAS7 cells formed significantly smaller tumors and yielded dramatically fewer metastatic lesions than sham-transfected cells (Table 1). These observations indicate that cancer cell-derived GPC1 is important for intrapancreatic tumor growth and suggest that GPC1 also contributes to the metastatic potential of pancreatic cancer cells. Metastasis was also markedly decreased in GPC1 $1^{-/}$mice, using either PANC-1 (Table 2) or T3M4 (Table 3) cells. The attenuated metastasis observed with T3M4-derived tumors was not due to decreased intrapancreatic growth of these tumors, indicating that host-derived GPC1 favors the metastatic propensity of pancreatic cancer cells independently of tumor size. Moreover, tumors from both cell types exhibited a marked decrease in angiogenesis, indicating that host-derived

\section{Figure 11}

Comparison of metastases in WT and GPC1-null mice. PANC-1 (A and B) and T3M4 (C and $\mathbf{D})$ human pancreatic cancer cells were injected into the pancreas of WT (A and $\mathbf{C}$ ) and GPC1-null (B and $\mathbf{D})$ mice, as described in the legends to Table 2 (PANC-1) and Table 3 (T3M4). Metastatic lesions were visible in the mesentery of WT mice, but not in GPC1-null mice.

GPC1 is also important for tumor angiogenesis within the pancreatic microenvironment.

We believe our findings are the first to demonstrate that GPC1 modulates the metastatic potential of pancreatic cancer cells. Moreover, the GPC1 effect was not limited to such cells, inasmuch as murine B16-F10 melanoma cells formed fewer pulmonary metastases in the GPC1/- mice. Several mechanisms may explain these observations. First, decreased GPC1 levels may attenuate metastasis by interfering with tumor angiogenesis. For example, the VEGFR tyrosine kinase inhibitor PTK 787 (38) and the chimeric protein VEGF Trap (39), in addition to suppressing angiogenesis, markedly attenuate the ability of pancreatic cancer cells to metastasize. Second, low GPC1 levels may interfere with GPC1dependent regulatory effects on syndecan-1 shedding, resulting in a microenvironment that is not receptive to metastatic growth $(32,40-42)$. Third, GPC1 in the tumor microenvironment enhances the storage of growth factors, promoting both their stability and their ability to act as morphogens $(43,44)$. Thus low levels of GPC1 may decrease the availability of stored growth factors. Fourth, angiopoietin- 2 promotes breast cancer invasion and metastasis through an $\alpha 5 \beta 1$ integrin-mediated mechanism (45), whereas Tie 2 expression in gliomas enhances tumor progression due to aberrant autocrine activation through angiopoietin-1and integrin $\beta 1$-dependent pathways (18). It is therefore possible that the presence of Tie 2 on the surface of pancreatic cancer cells (Figure 10C) and the abundance of integrins in PDAC (46) promotes pancreatic cancer cell metastasis and that this metastatic pathway is attenuated in the absence of GPC1. In view of the importance of angiogenic and metastatic processes in PDAC (34) and the recognized contributions of tumor angiogenesis to the metastatic process (47), taken together, the present findings suggest that targeting GPC1 may ultimately yield novel therapeutic options in the treatment of PDAC and its metastatic lesions.

\section{Table 1}

Effects of suppressing cancer cell GPC1 on tumor metastasis

$\begin{array}{lccc}\text { Parameter } & \text { Sham } & \text { GAS6 } & \text { GAS7 } \\ \text { Primary tumor volume }\left(\mathrm{mm}^{3}\right) & 823 \pm 89 & 567 \pm 55^{\mathrm{A}} & 492 \pm 59^{\mathrm{B}} \\ \text { Mice with lymph node metastasis } & 10 & 2^{\mathrm{C}} & 1^{\mathrm{C}} \\ \text { Total local lymph nodes } & 31 & 3 & 1 \\ \text { Total mesenteric region nodes } & 23 & 0 & 0 \\ \text { Mice with peritoneal } & 2 & 0 & 0 \\ \quad \text { dissemination/ascites } & & & \end{array}$

Sham-transfected or GAS PANC-1 cells $\left(2 \times 10^{6} /\right.$ site $)$ were injected into the pancreas of nude mice, using 28-gauge needles. Six weeks later, the volumes of the intrapancreatic tumors and the extent of metastatic involvement were determined. Data are means \pm SEM from 10 mice per group. ${ }^{A} P<0.03,{ }^{B} P<0.01$, and ${ }^{C} P<0.001$ compared with control. Statistical analysis was not carried out with respect to local and mesenteric lymph node disease or peritoneal involvement. 


\section{Table 2}

Effects of host-derived GPC1 on PANC-1 metastasis

$\begin{array}{lcc}\text { Mouse } & \text { WT } & \text { GPC1-/ } \\ \text { Mice with tumor } & 7 / 7 & 5 / 8 \\ \text { Tumor volume }\left(\mathrm{mm}^{3}\right) & 1,983 \pm 307 & 1,113 \pm 356^{A} \\ \text { Lymph node metastasis (no.) } & 319 & 0 \\ \text { Liver metastasis (no.) } & 4 & 0 \\ \text { Spleen metastasis (no.) } & 1 & 0 \\ \text { Microvessel density (\% area) } & 5.8 \pm 0.5 & 2.8 \pm 0.5^{\mathrm{B}}\end{array}$

Sham-transfected PANC- 1 cells $\left(2 \times 10^{6} /\right.$ site $)$ were injected into the pancreas of WT nude and GPC1-null nude mice, using 28-gauge needles. Ten weeks later, the volumes of the intrapancreatic tumors and the extent of metastatic involvement were determined. Tumor volumes are means \pm SEM of measurements from 7 WT mice (1 mouse in this group was found dead 2 weeks after cancer cell injection) and 5 GPC1-null mice (3 mice in this group did not develop any grossly visible tumor during the 10-week period). Values for microvessel density were calculated as described in Methods. ${ }^{A} P<0.05$ and ${ }^{B} P<0.0005$ compared with WT. Statistical analysis was not carried out with respect to lymph node involvement.

\section{Methods}

Materials. The following materials were purchased from the following companies: DMEM, RPMI 1640, and trypsin-EDTA from Mediatech Inc.; FBS from Omega Scientific Inc.; G418 from GIBCO Laboratories; Noble agar from Difco Laboratories; recombinant human EGF from Chemicon; Heparitinase and Chondroitinase ABC Protease Free from Seikagaku Corporation; One Solution reagent and anti-phospho-MAPK antibody from Promega; Immobilon-P PVDF membranes from Millipore Corp.; RNeasy Mini Kit from Qiagen; phosphatidylinositol-specific phospholipase C (PI-PLC) from Molecular Probes; magnetic dynabeads from Dynal Biotech from Invitrogen; SulfoLink Coupling Gel from Pierce Biotechnology; anti-ERK-2 antibody, anti-angiopoietin- 1 and -2 antibodies, and anti-Tie2 antibody from Santa Cruz Biotechnology Inc.; anti-CD31 rat anti-mouse monoclonal antibody (catalog no. 553370) and anti-VE cadherin antibody from Pharmingen; anti-PCNA monoclonal antibody from Novocastra; Antigen Unmasking Solution from Vector Laboratories; ApopTag in situ apoptosis detection kit from Chemicon; oligonucleotide primers from Applied Biosystems; PANC-1 human pancreatic cancer cells and COS-7 cells from American Type Culture Collection. Murine B16-F10 melanoma cells were a gift from Mary Jo Turk (Dartmouth Medical School, Hanover, New Hampshire, USA) and T3M4 human pancreatic carcinoma cells were a gift from R.S. Metzger at Duke University (Durham, North Carolina, USA). Athymic nude mice were obtained from Harlan. The following recombinant human growth factors were gifts: HB-EGF and FGF2 from Scios Nova Inc. and IGF-1 and VEGF-A from Genentech.

GPC1-knockout mice were produced by targeted mutagenesis in embryonic stem cells and maintained by backcrossing for more than 9 generations onto a CD-1 background prior to establishment of a homozygous null colony. The targeting construct directed the deletion of a large portion of the first exon of the GPC1 gene, removing both the translational start site and the signal peptide, and yielded homozygous animals in which GPC1 mRNA is greatly reduced and GPC1 protein is undetectable. Homozygotes are viable and fertile.

Stable transfection. The GPC1 antisense construct was prepared by RTPCR amplification of human placenta cDNA, as described previously (11). Stable transfection of GPC1-AS-1751 into PANC-1 cells was performed by using the lipofectamine method (12), and single clones were isolated after 3-4 weeks. After expansion, cells from each individual clone were screened for expression of GPC1 sense and antisense mRNA by northern blot analysis. Parental PANC-1 cells also were transfected with an empty expression vector carrying the neomycin-resistance gene as a control. Positive clones were routinely grown in selection medium.

Cell culture and growth assay. PANC-1 human pancreatic cancer cells were grown in DMEM supplemented with 6\% FBS (complete medium). T3M4 cells were grown in RPMI 1640 supplemented with 7\% FBS. COS-7 cells were grown in DMEM supplemented with 10\% FBS. Murine B16-F10 melanoma cells were grown in RPMI 1640 supplemented with 5\% FBS and $5 \mu \mathrm{M} \beta$-mercaptonethanol. All media were supplemented with $100 \mathrm{U} / \mathrm{ml}$ penicillin and $100 \mu \mathrm{g} / \mathrm{ml}$ streptomycin. Medium for the melanoma cells also contained amphotericin B $(2.5 \mu \mathrm{g} / \mathrm{ml})$. All cells were cultured at $37^{\circ} \mathrm{C}$ in humidified air with $5 \% \mathrm{CO}_{2}$.

Anchorage-dependent growth was assessed by cell counting with a hemacytometer, after plating $2.0 \times 10^{4}$ cells/well in 6-well plates and incubating in complete medium. Cell doubling times were then calculated. Anchorage-independent growth was assessed by double-layer soft agar assay, as previously reported (48). Briefly, $3.0 \times 10^{3}$ viable cells were suspended in complete medium containing $0.3 \%$ agar and seeded in triplicate in 6 -well plates onto a base layer of complete medium containing $0.5 \%$ agar. Complete medium $(1 \mathrm{ml}$ ) containing $0.3 \%$ agar was added every 5 days.

To assess the mitogenic effects of growth factors, cells were plated in $1 \mathrm{ml}$ of serum-free DMEM containing $0.1 \%$ BSA, $5 \mu \mathrm{g} / \mathrm{ml}$ transferrin, $5 \mathrm{ng} / \mathrm{ml}$ sodium selenite, antibiotics, and $0.3 \%$ agar in the absence or presence of growth factors. EGF, FGF-2, HB-EGF, or IGF-I, each a concentration of $1 \mathrm{nM}$, were added every 4 days. After 14 days, colonies consisting of more than 10 cells were counted by microscopy using an Inverted Diaphot 300 microscope (Nikon Inc.).

Generation of GPC1-knockout mice on an athymic background. The nude and GPC1 loci are on separate chromosomes, making it straightforward to generate mice that are homozygous for both. Briefly, GPC1/- and $\mathrm{GPC}^{+/+}$animals were crossed with $\mathrm{nu} / \mathrm{nu}$ and $\mathrm{nu} /+$ animals to yield $\mathrm{GPC}^{+/-} \mathrm{nu} /+\mathrm{F} 1$ hybrids. These were bred inter se, to yield an F2 generation of $\mathrm{nu} / \mathrm{nu}$ and $\mathrm{nu} /+$ animals from which only those that were $\mathrm{GPC} 1^{+/+}$ and $\mathrm{GPC}^{-/-}$were kept. Twenty one of each of these groups were bred inter se (avoiding brother-sister matings) to yield offspring of which only those that were $\mathrm{GPC} 1^{+/+} \mathrm{nu} / \mathrm{nu}$ and $\mathrm{GPC} 1^{-/-} \mathrm{nu} / \mathrm{nu}$ were kept, and these F3 mice were used for experiments.

In vivo tumorigenicity assays and tissue preparation. To assess the effects of GPC1 suppression on tumorigenicity, $1 \times 10^{6}$ sham-transfected or GAS

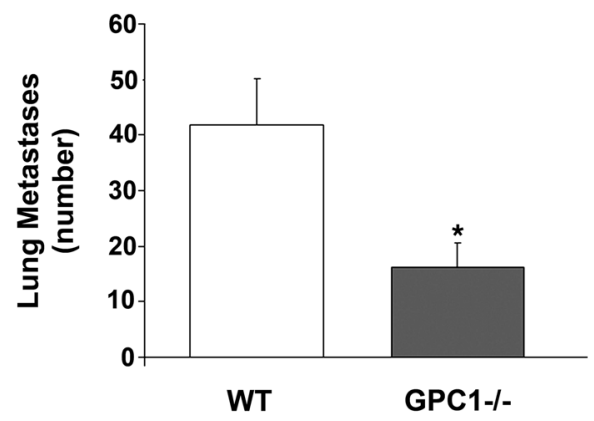

Figure 12

Effect of endogenous GPC1 levels on pulmonary metastasis of murine melanoma cells. Exponentially growing $\left(1 \times 10^{5}\right)$ murine B16-F10 melanoma cells were injected into the lateral vein of mice. Pulmonary metastases were counted 20-25 days later. Data are means \pm SEM from 16 WT mice and 20 GPC1-null mice. ${ }^{*} P<0.006$ compared with WT. 
Table 3

Effects of host-derived GPC1 on T3M4 metastasis

$\begin{array}{lcc}\text { Mouse } & \text { WT } & \text { GPC1-/ } \\ \text { Mice with tumor } & 7 / 7 & 8 / 8 \\ \text { Tumor volume }\left(\mathrm{mm}^{3}\right) & 1,088 \pm 289 & 1,115 \pm 447 \\ \text { Lymph node metastasis (no.) } & 7 & 0 \\ \text { Liver metastasis (no.) } & 6 & 0 \\ \text { Spleen metastasis (no.) } & 7 & 0 \\ \text { Microvessel density (\% area) } & 2.9 \pm 0.6 & 1.4 \pm 0.3^{\mathrm{A}}\end{array}$

T3M4 cells $\left(2 \times 10^{5} /\right.$ site $)$ were injected into the pancreas of WT nude and GPC1-null nude mice, using 28-gauge needles. Four weeks later, the volumes of the intrapancreatic tumors and the extent of metastatic involvement were determined. Tumor volumes are means \pm SEM of measurements from 7 WT mice and 8 GPC1-null mice. Calculation of microvessel area was performed as described in Methods. ${ }^{A} P<0.04$ when compared with WT. Tumor volumes were similar in both groups of mice. Statistical analysis was not carried out with respect to lymph node involvement.

PANC-1 cells were injected subcutaneously into the flank region on one side of a 4- to 6-week-old, female athymic (nude) mouse. The animals were monitored for tumor formation every week and killed 8-15 weeks after injection when the tumor diameter became $15 \mathrm{~mm}^{3}$. Tumor volume was calculated as $\pi / 4 \times$ width $\times$ height $\times$ length of the tumor, as previously reported (48). Tumors were rapidly excised and divided into 3 fragments. One tumor fragment was snap frozen in liquid nitrogen and stored at $-80^{\circ} \mathrm{C}$. Another tumor fragment was embedded in OCT, frozen in liquid nitrogen, and stored at $-80^{\circ} \mathrm{C}$ for subsequent staining with anti-CD31 antibody (49). The third tumor fragment was fixed in formalin and embedded in paraffin for subsequent immunohistochemical staining.

For orthotopic inoculation of cancer cells, parental, sham-transfected or GPC1 antisense-transfected PANC- 1 cells $\left(2 \times 10^{6}\right)$ or parental T3M4 cells $\left(2 \times 10^{5}\right)$ were injected into the pancreas of 4 - to 6-week-old female athymic (nude) mice, using 28-gauge needles. Passage through this size needle did not alter cellular viability and was not associated with leaking from the injection site. At autopsy, the size of the intrapancreatic tumors was measured and the tumor volume was determined as above (48), and the number of metastatic lymph nodes was counted.

To perform studies with melanoma cells, exponentially growing murine B16-F10 melanoma cells were harvested, washed, and resuspended in PBS. Cells (100,000 in $250 \mu \mathrm{l}$ of PBS) were injected into the lateral vein of the mice. Mice were watched daily starting at day 14 after injection, and in 4 separate experiments using 4 to 5 mice per group, they began to appear ill due to lung tumor burden $20-25$ days following the injection. All the mice in each experiment were sacrificed on the same day, as soon as they appeared ill. The lungs were immediately removed and placed briefly in PBS containing $3 \%$ hydrogen peroxide and $10 \%$ buffered formalin. The number of pulmonary metastases was then counted. All studies with mice were approved by Dartmouth Medical School Institutional Animal Care and Use Committee.

Immunoblotting. Sham- and GAS cells and tissue samples were lysed in lysis buffer containing $50 \mu \mathrm{g} / \mathrm{ml}$ aprotinin, $10 \mu \mathrm{g} / \mathrm{ml}$ leupeptin, $10 \mu \mathrm{g} / \mathrm{ml}$ pepstatin $\mathrm{A}, 10 \mu \mathrm{g} / \mathrm{ml}$ benzamidine, and $1 \mathrm{mM} \mathrm{PMSF}$ (50). GPC1 generally appears on immunoblots as broad, faintly stained high-molecularweight smears, in part due to poor binding of proteoglycans to blotting membranes (11). However, after digestion with heparitinase (to remove HSs) or heparitinase in conjunction with chondroitinaseABC (to also remove chondroitin sulfates), GPC1 migrates as a relatively distinct band on SDS-PAGE. Therefore, when performing immunoblotting for
GPC1, cell lysates were first incubated in the absence or presence of these enzymes for $3 \mathrm{~h}$ at $37^{\circ} \mathrm{C}$ and subjected to SDS-PAGE and electrotransferred to Immobilon-P membrane. To study conditioned media, shamtransfected and GAS cells were incubated with PI-PLC and heparitinase for $1 \mathrm{~h}$. Following concentration in a Microcon YM-10, media proteins were subjected to SDS-PAGE and electrotransferred to ImmobilonP PVDF membranes. After blocking, membranes were blotted with an affinity-purified rabbit anti-human GPC1 antibody and with a secondary horseradish peroxidase-conjugated antibody. Bound antibody was visualized using enhanced chemiluminescence.

To assess the consequences of altered GPC1 levels on MAPK activation, membranes were stripped for $30 \mathrm{~min}$ at $50^{\circ} \mathrm{C}$ in buffer containing $2 \%$ SDS, $62.5 \mathrm{mM}$ Tris (pH 6.7), and $100 \mathrm{mM}$ 2-mercaptoethanol and blotted with an anti-phospho-ERK (anti-active MAPK) antibody. To confirm equal loading of lanes, membranes were stripped again and blotted with an anti-ERK2 antibody.

Immunohistochemistry of paraffin-embedded and frozen tissues. Paraffinembedded tumor tissues were sectioned ( $5 \mu \mathrm{m}$ thick), mounted on polyL-lysine-coated glass slides, and allowed to dry overnight at $23^{\circ} \mathrm{C}$. These sections were used for detection of PCNA and apoptosis by the ApopTag TUNEL assay, as previously reported $(50,51)$.

PCNA, angiopoietin-1, angiopoietin-2, and Tie2 immunostaining was performed using the streptavidin-peroxidase technique (VECTASTAIN $\mathrm{ABC}$ Kit; Vector Labs). After deparaffinization, antigen retrieval was performed by heating in a microwave oven $\left(95^{\circ} \mathrm{C}\right.$ ) for $5 \mathrm{~min}$ in $10 \mathrm{mM}$ citrate buffer at pH 6.0 (PCNA) or by using a 2100-Retriever (PickCell Laboratories) and Antigen Unmasking Solution (angiopoietin-1, angiopoietin-2, and Tie2). Sections were then incubated for $10 \mathrm{~min}$ with $3 \%$ hydrogen peroxide to block endogenous peroxidase activity, for $30 \mathrm{~min}$ at $23^{\circ} \mathrm{C}$ with $5 \%$ normal goat serum, and overnight at $4{ }^{\circ} \mathrm{C}$ with a monoclonal antiPCNA antibody $(2 \mu \mathrm{g} / \mathrm{ml})$. Bound antibody was detected with biotinylated anti-mouse IgG and VECTASTAIN ABC Reagent (Vector Labs) complex, using diaminobenzidine tetrahydrochloride (DAB) as the substrate (50). Some sections were incubated without primary antibodies and did not yield positive immunoreactivity.

Two types of immunostaining procedures were performed to assess microvessel density. First, for tumor tissues frozen in OCT, sections ( $5 \mu \mathrm{m}$ thick) were mounted on poly-L-lysine-coated glass slides and airdried overnight at $23^{\circ} \mathrm{C}(49,50)$. Frozen tissue sections were fixed in acetone for $5 \mathrm{~min}$, and endogenous peroxidase activity was blocked by incubation for $10 \mathrm{~min}$ with $3 \%$ hydrogen peroxide. Samples were then incubated

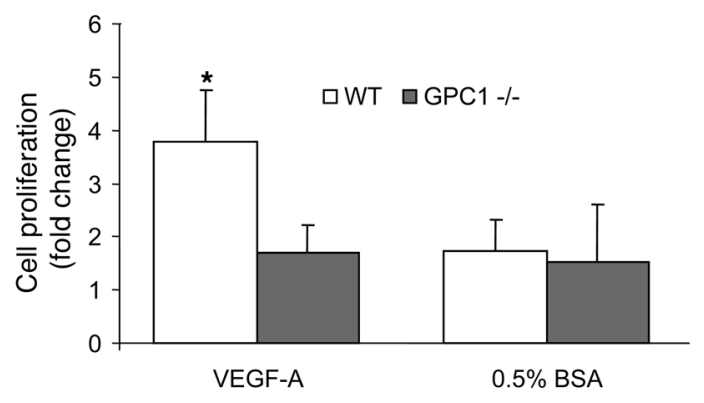

\section{Figure 13}

Effects of endogenous GPC1 levels on endothelial cell proliferation. Endothelial cells isolated from WT or GPC1-null mice were plated in triplicate on fibronectin-coated 96-well plates, serum-starved overnight, and incubated for $48 \mathrm{~h}$ in the presence of $0.5 \% \mathrm{BSA}$ (control) or $50 \mathrm{ng} / \mathrm{ml}$ VEGF-A. Data are means \pm SEM. ${ }^{*} P<0.05$ compared with control. 


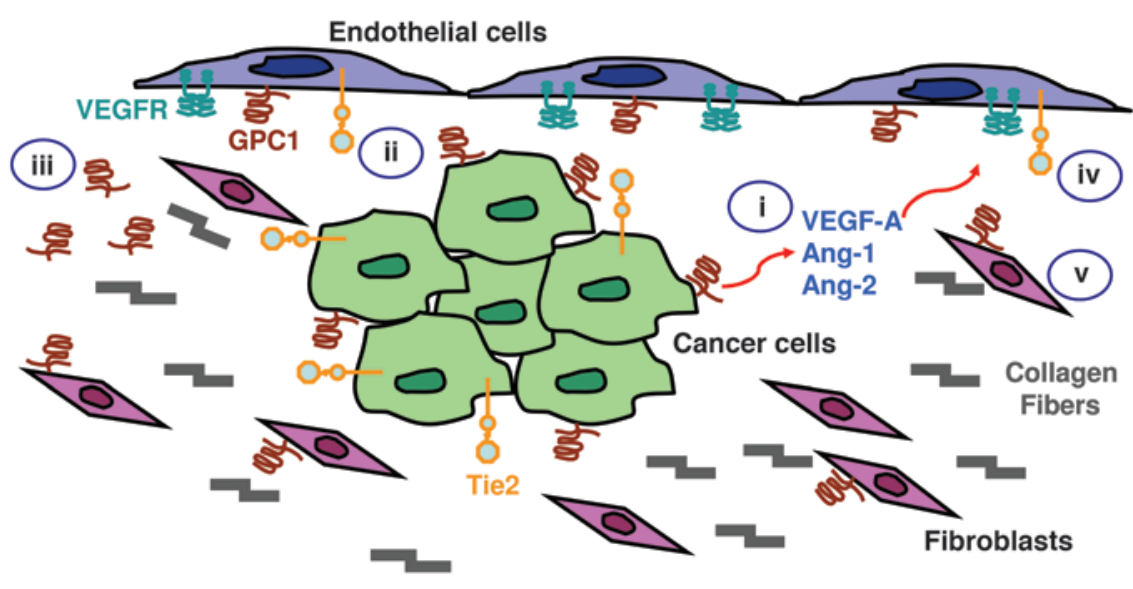

\section{Figure 14}

Schematic representation of the role of GPC1 in tumor angiogenesis and metastasis. Endothelial cells expressing VEGF receptors, Tie2, and GPC1 (iv) are shown interacting with cancer cell-derived VEGF-A, angiopoietin-1, and angiopoietin-2 (i), cancer cell-derived GPC1 acting in trans (ii), shed GPC1 (iii), and fibroblast-derived GPC1 (v). Thus host- and tumor-derived GPC1 combine to contribute to tumor angiogenesis. for $30 \mathrm{~min}$ at $23^{\circ} \mathrm{C}$ with $5 \%$ normal rabbit serum in PBS and overnight at $4^{\circ} \mathrm{C}$ with monoclonal anti-CD31 antibody $(1 \mu \mathrm{g} / \mathrm{ml})$. Bound antibody was detected with biotinylated rabbit anti-rat IgG secondary antibody and streptavidin-peroxidase complex, using DAB as the substrate. Second, for paraffin embedded tissues, endothelial cells were detected with the anti-VE cadherin antibody. Sections in both of the above procedures were counterstained with Mayer's hematoxylin.

To identify individual apoptotic cells in tissue sections, the TUNEL method consisting of the ApopTag in situ apoptosis detection kit (BD Pharmingen) that specifically recognizes 3 '-OH DNA ends generated by DNA fragmentation was used according to the manufacturer's directions, as previously described (51). Briefly, deparaffinized and proteinase $\mathrm{K}-$ digested tissue sections were incubated for $60 \mathrm{~min}$ at $37^{\circ} \mathrm{C}$ with terminal deoxynucleotidyl transferase (TdT) enzyme and digoxigenin-dUTP after blocking of endogenous peroxidase activity. Digoxigenin residues catalytically bound to the DNA 3'-OH ends by TdT were detected by antidigoxigenin antibodies conjugated with peroxidase, using DAB as the substrate, followed by counterstaining with methyl green. Omission of TdT enzyme did not yield any immunoreactivity.

To perform quantitative morphometry, the stained slides were analyzed with Image-Pro Plus (Media Cybernetics), as previously reported (50). Three fields at $\times 100$ magnification were chosen randomly from each tumor for CD31 staining, and 5 fields at $\times 200$ magnification were analyzed following TUNEL and PCNA staining.

Anti-peptide antibodies. Anti-GPC1 antibodies were generated by Genemed Synthesis Inc., using a peptide corresponding to amino acid residues 343 to 360 of human GPC1 (CGNPKVNPQGPGPEEKRR) that was synthesized and conjugated to keyhole limpet hemocyanin as previously reported (52). Following purification over Sephadex G-25 column, the peptide conjugate was injected intradermally into rabbits, using complete Freund's adjuvant.

For affinity purification of the antibody, the purified peptide immunogen (10 mg) was coupled to SulfoLink Coupling Gel (Pierce Biotechnology) according to the manufacturer's protocol. The anti-GPC1 antibody was purified using a $0.5-\mathrm{ml}$ column equilibrated with PBS. The antibody was eluted with $50 \mathrm{mM}$ glycine $/ 0.15 \mathrm{M} \mathrm{NaCl}(\mathrm{pH} 2.5)$ and neutralized with $1 \mathrm{M}$ Tris buffer. The fractions with the highest reading at $280 \mathrm{OD}$ were pooled (final pH 8.5), and the antibody was dialyzed overnight in PBS.

COS-7 cells were transiently transfected using lipofectamine with a construct encoding GPC1 fused to alkaline phosphatase, termed "APT6GPC1" (13). The medium was collected 3-5 days after transfection, filtered, and stored at $-80^{\circ} \mathrm{C}$ until use. An antigen-capture ELISA was performed to determine the affinity of the purified antibody, using 96 -well Nunc Immunoplates (Nunc) that were coated with Protein A $(50 \mu \mathrm{g} / \mathrm{ml})$ for $1 \mathrm{~h}$ at $37^{\circ} \mathrm{C}$. After washing with PBS, medium from the APT6-GPC1-transfected COS-7 cells that had been heat inactivated for $10 \mathrm{~min}\left(65^{\circ} \mathrm{C}\right)$ was added to the plates, and incubation was continued for $2 \mathrm{~h}$ at $37^{\circ} \mathrm{C}$. After washing, p-nitrophenol phosphate (in $2 \mathrm{M}$ diethanolamine, $\mathrm{pH} 8.8,1 \mathrm{mg} / \mathrm{ml} \mathrm{BSA}$, and $1 \mathrm{mM} \mathrm{MgCl}$ ) was added to each well. Incubations were continued at $37^{\circ} \mathrm{C}$ for $20 \mathrm{~min}$ and reactions terminated by adding $0.5 \mathrm{M} \mathrm{NaPO}_{4}$ ( $\mathrm{pH}$ 8.0). OD readings were performed on a microplate reader at $405 \mathrm{~nm}$.

Endothelial cell isolation and proliferation assay. Primary endothelial cells were isolated from adult mouse livers following mechanical mincing and collagenase $(2 \mathrm{mg} / \mathrm{ml})$ digestion for $30 \mathrm{~min}$ at $37^{\circ} \mathrm{C}$. Cells were isolated by incubating for $30 \mathrm{~min}$ at $23^{\circ} \mathrm{C}$ with magnetic Dynabeads (Invitrogen) labeled with anti-CD31 antibodies and using a magnetic separator (53). Cells were then incubated in DMEM supplemented with 20\% FBS, penicillin/streptomycin $(100 \mathrm{U} / \mathrm{ml})$, heparin $(100 \mu \mathrm{g} / \mathrm{ml})$, endothelial cell growth factor $(100 \mu \mathrm{g} /$ $\mathrm{ml}), 1 \times$ nonessential amino acids, $2 \mathrm{mM}$ L-glutamine, $1 \times$ sodium pyruvate, gentamicin $(58 \mu \mathrm{g} / \mathrm{ml})$, and amphotericin B $(25 \mathrm{ng} / \mathrm{ml})$, termed "complete endothelium medium." To assess the effects of VEGF-A on endothelial cell proliferation, cells from passage 1 or 2 were plated for $4 \mathrm{~h}$ in 96 -well cell culture plates coated with fibronectin $(5 \mu \mathrm{g} / \mathrm{ml})$ at a density of 4,000 cells per well. The medium was then replaced with fresh complete endothelium medium containing $2 \% \mathrm{FBS}$ and $0.5 \% \mathrm{BSA}$. Cells were incubated at $37^{\circ} \mathrm{C}$ for $48 \mathrm{~h}$ in the absence or presence of $50 \mathrm{ng} / \mathrm{ml}$ VEGF-A, prior to the addition of One Solution reagent (Promega) for $2 \mathrm{~h}$. Optical density was then determined at $490 \mathrm{~nm}$ on a Molecular Devices microplate reader.

Preparation of mouse embryonic fibroblasts. Primary MEFs were isolated from 13.5-day-old embryos by trypsin digestion. The cells were resuspended in DMEM containing $8 \% \mathrm{FBS}, 100 \mathrm{U} / \mathrm{ml}$ penicillin/streptomycin, and $25 \mathrm{ng} / \mathrm{ml}$ amphotericin B. Following plating on tissue culture plates and incubation at $37^{\circ} \mathrm{C}$ with $5 \% \mathrm{CO}_{2}$, cells were collected for RNA isolation.

Quantitative real-time PCR. To assess expression of proangiogenic factors in the tumors, RNA extraction, RT-PCR, and first-strand cDNA synthesis for quantitative real-time PCR analysis (Q-PCR) were carried out as described previously $(54,55)$. Target gene sequences were from the National Center for Biotechnology Information GenBank databases. Q-PCR was performed using an ABI PRISM 7300 sequence detection system (Applied Biosystems). RNA expression was calculated based on a relative standard curve representing 4-fold dilutions of human cDNA. Q-PCR data were expressed as a relative quantity based on the ratio of the fluorescent change observed with the target gene to the fluorescent change observed with $18 \mathrm{~S}$ ribosomal subunit. Hepatic endothelial cell and MEF RNA samples were isolated with the Qiagen RNeasy kit following the manufacturer's directions, and Q-PCR was performed as described above, using the Applied Biosystems TaqMan Assay with prevalidated murine probes and primer 
sets. A dilution series was carried out for each gene, and the $18 \mathrm{~S}$ ribosomal subunit was used as an internal control.

Statistics. Unless otherwise indicated, Student's $t$ test was used for statistical analysis, with $P<0.05$ defined as significant.

\section{Acknowledgments}

This study was supported in part by the US Public Health Service grant CA-101306 to M. Korc.

1. McKenna, S., and Eatock, M. 2003. The medical management of pancreatic cancer: a review. Oncologist. 8:149-160.

2. Jemal, A., et al. 2007. Cancer statistics. CA CancerJ. Clin. 57:43-66.

3. Perrimon, N., and Bernfield, M. 2001. Cellular functions of proteoglycans - an overview. Semin. Cell Dev. Biol. 12:65-67.

4. De Cat, B., and David, G. 2001. Developmental roles of the glypicans. Semin. Cell Dev. Biol. 12:117-125.

5. Filmus, J. 2001. Glypicans in growth control and cancer. Glycobiology. 11:19R-23R.

6. Delehedde, M., Lyon, M., Sergeant, N., Rahmoune, H., and Fernig, D.G. 2001. Proteoglycans: pericellular and cell surface multireceptors that integrate external stimuli in the mammary gland. J. Mammary Gland Biol. Neoplasia. 6:253-273.

7. Esko, J.D., and Selleck, S.B. 2002. Order out of chaos: assembly of ligand binding sites in heparan sulfate. Annu. Rev. Biochem. 71:435-471.

8. David, G. 1993. Integral membrane heparan sulfate proteoglycans. FASEB J. 7:1023-1030.

9. Veugelers, M., et al. 1999. Glypican-6, a new member of the glypican family of cell surface heparan sulfate proteoglycans. J. Biol. Chem. 274:26968-26977.

10. Rapraeger, A.C. 1995. In the clutches of proteoglycans: how does heparan sulfate regulate FGF binding? Chem. Biol. 2:645-649.

11. Kleeff, J., et al. 1998. The cell-surface heparan sulfate proteoglycan glypican-1 regulates growth factor action in pancreatic carcinoma cells and is overexpressed in human pancreatic cancer. J. Clin. Invest. 102:1662-1673.

12. Kleeff, J., et al. 1999. Stable transfection of a glypican-1 antisense construct decreases tumorigenicity in PANC-1 pancreatic carcinoma cells. Pancreas. 19:281-288.

13. Chen, R.L., and Lander, A.D. 2001. Mechanisms underlying preferential assembly of heparan sulfate on glypican-1. J. Biol. Chem. 276:7507-7517.

14. Kobrin, M.S., et al. 1994. Induction and expression of heparin-binding EGF-like growth factor in human pancreatic cancer. Biochem. Biophys. Res. Commun. 202:1705-1709.

15. Ebert, M., et al. 1994. Induction and expression of amphiregulin in human pancreatic cancer. Cancer Res. 54:3959-3962.

16. Partanen, J., and Dumont, D.J. 1999. Functions of Tie 1 and Tie 2 receptor tyrosine kinases in vascular development. Curr. Top. Microbiol. Immunol. 237:159-172.

17. Hendrix, M.J., Seftor, E.A., Kirschmann, D.A., and Seftor, R.E. 2000. Molecular biology of breast cancer metastasis. Molecular expression of vascular markers by aggressive breast cancer cells. Breast Cancer Res. 2:417-422.

18. Lee, O.H., et al. 2006. Expression of the receptor tyrosine kinase Tie2 in neoplastic glial cells is associated with integrin beta1-dependent adhesion to the extracellular matrix. Mol. Cancer Res. 4:915-926.

19. Davis, S., and Yancopoulos, G.D. 1999. The angiopoietins: Yin and Yang in angiogenesis. Curr. Top. Microbiol. Immunol. 237:173-185.

20. Kim, I., et al. 2000. Angiopoietin-2 at high concentration can enhance endothelial cell survival through the phosphatidylinositol 3'-kinase/Akt signal transduction pathway. Oncogene. 19:4549-4552.
Received for publication April 16, 2007, and accepted in revised form October 17, 2007.

Address correspondence to: Murray Korc, Department of Medicine, One Medical Center Drive, Dartmouth Hitchcock Medical Center, Lebanon, New Hampshire 03756, USA. Phone: (603) 650-7936; Fax: (603) 650-6122; E-mail: murray.korc@ dartmouth.edu.
21. Kwak, H.J., So, J.N., Lee, S.J., Kim, I., and Koh, G.Y. 1999. Angiopoietin-1 is an apoptosis survival factor for endothelial cells. FEBS Lett. 448:249-253.

22. Lobov, I.B., Brooks, P.C., and Lang, R.A. 2002. Angiopoietin-2 displays VEGF-dependent modulation of capillary structure and endothelial cell survival in vivo. Proc. Natl. Acad. Sci. U. S. A. 99:11205-11210.

23. Tait, C.R., and Jones, P.F. 2004. Angiopoietins in tumours: the angiogenic switch. J. Pathol. 204:1-10.

24. Carmeliet, P., and Jain, R.K. 2000. Angiogenesis in cancer and other diseases. Nature. 407:249-257.

25. Itakura, J., et al. 1997. Enhanced expression of vascular endothelial growth factor in human pancreatic cancer correlates with local disease progression. Clin. Cancer Res. 3:1309-13016.

26. Oh, H., et al. 1999. VEGF Hypoxia and vascular endothelial growth factor selectively up-regulate angiopoietin-2 in bovine microvascular endothelial cells. J. Biol. Chem. 274:15732-15739.

27. Fuster, M.M., et al. 2007. Genetic alteration of endothelial heparan sulfate selectively inhibits tumor angiogenesis. J. Cell Biol. 177:539-549.

28. Hansel, D.E., Kern, S.E., and Hruban, R.H. 2003. Molecular pathogenesis of pancreatic cancer. Annu. Rev. Genomics Hum. Genet. 4:237-256.

29. Korc, M. 1998. Role of growth factors in pancreatic cancer. Surg. Oncol. Clin. N. Am. 7:25-41.

30. Lander, A.D., Stipp, C.S., and Ivins, J.K. 1996. The glypican family of heparan sulfate proteoglycans: major cell-surface proteoglycans of the developing nervous system. Perspect. Dev. Neurobiol. 3:347-358.

31. McKeehan, W.L., Wang, F., and Kan, M. 1998. The heparan sulfate-fibroblast growth factor family: diversity of structure and function. Prog. Nucleic Acid Res. Mol. Biol. 59:135-176.

32. Ding, K., Lopez-Burks, M., Sanchez-Duran, J.A., Korc, M., and Lander, A.D. 2005. Growth factorinduced shedding of syndecan-1 confers glypican-1 dependence on mitogenic responses of cancer cells. J. Cell Biol. 171:729-738.

33. Zhang, L., et al. 2003. Tumor-derived vascular endothelial growth factor up-regulates angiopoietin-2 in host endothelium and destabilizes host vasculature, supporting angiogenesis in ovarian cancer. Cancer Res. 63:3403-3412.

34. Jakobsson, L., et al. 2006. Heparan sulfate in trans potentiates VEGFR-mediated angiogenesis. Dev. Cell. 10:625-634.

35. Korc, M. 2003. Pathways for aberrant angiogenesis in pancreatic cancer. Mol. Cancer. 2:8-16.

36. Gengrinovitch, S., et al. 1999. Glypican-1 is a VEGF165 binding proteoglycan that acts as an extracellular chaperone for VEGF165. J. Biol. Chem. 274:10816-10822.

37. Qiao, D., Meyer, K., Mundhenke, C., Drew, S.A., and Friedl, A. 2003. Heparan sulfate proteoglycans as regulators of fibroblast growth factor-2 signaling in brain endothelial cells. Specific role for glypican-1 in glioma angiogenesis. J. Biol. Chem. 278:16045-16053.

38. Solorzano, C.C., et al. 2001. Inhibition of growth and metastasis of human pancreatic cancer growing in nude mice by PTK 787/ZK222584, an inhibitor of the vascular endothelial growth factor receptor tyrosine kinases. Cancer Biother. Radiopharm. 16:359-370.

39. Fukasawa, M., and Korc, M. 2004. Vascular endothelial growth factor-trap suppresses tumorigenicity of multiple pancreatic cancer cell lines. Clin. Cancer Res. 10:3327-3332.

40. Sanderson, R.D., Yang, Y., Suva, L.J., and Kelly, T. 2004. Heparan sulfate proteoglycans and heparanase - partners in osteolytic tumor growth and metastasis. Matrix Biol. 23:341-352.

41. Yang, Y., et al. 2007. Heparanase enhances syndecan-1 shedding: A novel mechanism for stimulation of tumor growth and metastasis. J. Biol. Chem. 282:13326-13333.

42. Su, G., Blaine, S.A., Qiao, D., and Friedl, A. 2007. Shedding of syndecan- 1 by stromal fibroblasts stimulates human breast cancer cell proliferation via FGF2 activation. J. Biol. Chem. 282:14906-14915.

43. Vlodavsky, I., et al. 1990. Extracellular matrix-resident growth factors and enzymes: possible involvement in tumor metastasis and angiogenesis. Cancer Metastasis Rev. 9:203-226.

44. Lander, A.D., Nie, Q., and Wan, F.Y. 2002. Do morphogen gradients arise by diffusion? Dev. Cell. 2:785-796.

45. Imanishi, Y., et al. 2007. Angiopoietin-2 stimulates breast cancer metastasis through the alpha(5)beta(1) integrin-mediated pathway. Cancer Res. 67:4254-4263.

46. Lohr, M., et al. 1996. Expression and function of receptors for extracellular matrix proteins in human ductal adenocarcinomas of the pancreas. Pancreas. 12:248-259.

47. Folkman, J. 2003. Angiogenesis and apoptosis. Semin. Cancer Biol. 13:159-167.

48. Kornmann, M., Arber, N., and Korc, M. 1998. Inhibition of basal and mitogen-stimulated pancreatic cancer cell growth by cyclin D1 antisense is associated with loss of tumorigenicity and potentiation of cytotoxicity to cisplatinum. J. Clin. Invest. 101:344-352.

49. Luo, J., et al. 2001. Pancreatic cancer cell-derived vascular endothelial growth factor is biologically active in vitro and enhances tumorigenicity in vivo. Int. J. Cancer 92:361-369.

50. Rowland-Goldsmith, M.A., et al. 2002. Soluble type II transforming growth factor-beta receptor attenuates expression of metastasis-associated genes and suppresses pancreatic cancer cell metastasis. Mol. Cancer Ther. 1:161-167.

51. Kornmann, M., Ishiwata, T., Maruyama, H., Beger, H.G., and Korc, M. 2000. Coexpression of FAS and FAS-ligand in chronic pancreatitis: correlation with apoptosis. Pancreas. 20:123-128.

52. Litwack, E.D., et al. 1998. Expression of the heparan sulfate proteoglycan glypican- 1 in the developing rodent. Dev. Dyn. 211:72-87.

53. Dong, Q.G., et al. 1997. A general strategy for isolation of endothelial cells from murine tissues. Characterization of two endothelial cell lines from the murine lung and subcutaneous sponge implants. Arterioscler. Thromb. Vasc. Biol. 17:1599-1604.

54. Ketterer, K., et al. 2003. Reverse transcription-PCR analysis of laser-captured cells points to potential paracrine and autocrine actions of neurotrophins in pancreatic cancer. Clin. Cancer Res. 9:5127-5136.

55. Fukahi, K., Fukasawa, M., Neufeld, G., Itakura, J., and Korc, M. 2004. Aberrant expression of neuropilin-1 and -2 in human pancreatic cancer cells. Clin. Cancer Res. 10:581-590. 